\title{
Correction to: A T-junction device allowing for two simultaneous orthogonal views: application to bubble formation and break-up
}

\author{
Davide Caprini $^{1} \cdot$ Giorgia Sinibaldi $^{1} \cdot$ Luca Marino $^{1} \cdot$ Carlo Massimo Casciola $^{1,2} \mathbb{D}$
}

Published online: 22 December 2018

(c) The Author(s) 2018

\section{Correction to: Microfluidics and Nanofluidics (2018) 22:85 https://doi.org/10.1007/s10404-018-2101-1}

The article 'A T-junction device allowing for two simultaneous orthogonal views: application to bubble formation and break-up', written by Davide Caprini, Giorgia Sinibaldi, Luca Marino, Carlo Massimo Casciola was originally published electronically on the publisher's internet portal (currently SpringerLink) on 30 July 2018 without open access. With the author(s)' decision to opt for Open Choice the copyright of the article changed on 14 December 2018 to (C) The Author(s) 2018 and the article is forthwith distributed under the terms of the Creative Commons Attribution 4.0 International License (http://creativecommons.org/licen ses/by/4.0/), which permits use, duplication, adaptation, distribution and reproduction in any medium or format, as long as you give appropriate credit to the original author(s) and the source, provide a link to the Creative Commons license and indicate if changes were made.

The original article has been updated.

Open Access This article is distributed under the terms of the Creative Commons Attribution 4.0 International License (http://creativeco mmons.org/licenses/by/4.0/), which permits unrestricted use, distribution, and reproduction in any medium, provided you give appropriate credit to the original author(s) and the source, provide a link to the Creative Commons license, and indicate if changes were made.

Publisher's Note Springer Nature remains neutral with regard to jurisdictional claims in published maps and institutional affiliations.

The original article can be found online at https://doi.org/10.1007/ s10404-018-2101-1.

Carlo Massimo Casciola

carlomassimo.casciola@uniroma1.it

1 Dipartimento di Ingegneria Meccanica e Aerospaziale, Universitá di Roma La Sapienza, Via Eudossiana 18, 00184 Roma, Italy

2 Center for Life Nano Science, Istituto Italiano di Tecnologia, Viale Regina Elena 291, 00163 Roma, Italy 